\title{
STUDIES ON WF-3161, A NEW ANTITUMOR ANTIBIOTIC
}

\author{
Kazuyoshi Umehara, Kunio Nakahara, Sumio Kiyoto, Morita Iwami, \\ masanori OKamoto, Hirokazu Tanaka, Masanobu Kohsaka, \\ Hatsuo AoKi and Hiroshi IMANAKA
}

Fermentation Research Laboratories, Fujisawa Pharmaceutical Co., Ltd., Osaka, Japan

(Received for publication December 10, 1982)

\begin{abstract}
WF-3161 is an antitumor antibiotic produced by a strain of fungus, Petriella guttulata. The antibiotic was purified by solvent extraction and a combination of silica gel and reverse phase column chromatography. The chemical structure of the antibiotic $\left(\mathrm{C}_{31} \mathrm{H}_{44} \mathrm{~N}_{4} \mathrm{O}_{6}, \mathrm{mp}\right.$ $181 \sim 183^{\circ} \mathrm{C}$ ) was found to be a cyclic tetrapeptide consisting of phenylalanine, leucine, pipecolinic acid and 2-amino-8-oxo-9,10-epoxydecanoic acid. WF-3161 inhibited the growth of Trichophyton asteroides. It prolonged survival period of mice bearing leukemia P-388 with a high therapeutic index.
\end{abstract}

In the course of our screening for new antitumor antibiotics one tentatively designated WF-3161 was isolated from the culture filtrate of Petriella guttulata No. 3161, from a soil sample collected at Kamakura City, Kanagawa Prefecture. This paper deals with taxonomic studies on the producing strain, the production and isolation procedures, and physicochemical and biological properties of WF3161.

Methods

Fermentation

The growth of Petriella guttulata No. 3161 on mature slant cultures was used to inoculate eight 500$\mathrm{ml}$ flasks containing $100 \mathrm{ml}$ each of sterile seed medium consisting of $2 \%$ corn starch, $0.5 \%$ glucose, $1.0 \%$ soy bean meal, $1 \%$ dried yeast and $1.0 \%$ corn steep liquor $(\mathrm{pH} 6.2)$. The flasks were shaken on a rotary shaker $\left(220 \mathrm{rpm}, 5.1 \mathrm{~cm}\right.$ throw) for 3 days at $30^{\circ} \mathrm{C}$. The content of the flasks was used to inoculate 160 liters of fermentation medium in a stainless steel fermentor. The composition of the medium was as follows: $1.5 \%$ soluble starch, $0.25 \%$ cotton seed meal, $0.25 \%$ gluten meal, $0.25 \%$ wheat germ, $0.25 \%$ dried yeast and $0.2 \% \mathrm{CaCO}_{3}$. Fermentation was allowed to proceed for 3 days at temperature of $30^{\circ} \mathrm{C}$, with air flow of 160 liters per minute and agitation of $250 \mathrm{rpm}$.

Detection of the Antibiotic

The antibiotic present in the fermentation broth or in preparations obtained during the purification process was detected by standard disc-agar diffusion assay using Trichophyton asteroides as a test organism.

Antitumor Activity

The antitumor activity of WF-3161 was determined in experimental tumor system on mice. Lymphocytic leukemia P-388 was implanted intraperitoneally into BDF $_{1}$ mice at an inoculum size of $1 \times 10^{6}$ cells per mouse. Twenty-four hours after the implantation of tumor cells, graded doses of the antibiotic which was suspended in $0.5 \%$ methylcellulose were administered to mice intraperitoneally. Treatments were given on day $1,2,3$, and 4 . Adriamycin was comparatively tested as reference compound. Death or survival of the treated and non-treated (control) animals was recorded daily. T/C is the ratio of the median survival time of the test group (T) divided by that of the control group (C). 
Assay for the Antimicrobial Activity

Antimicrobial activity was determined by the serial agar dilution streak method. One loopful of an overnight culture of each test organism in an appropriate medium was streaked on plates containing graded a concentration of the drug and the minimal inhibitory concentration (MIC) was expressed in terms of $\mu \mathrm{g} / \mathrm{ml}$ after incubation at $37^{\circ} \mathrm{C}$ for 18 hours for bacteria, and 48 to 72 hours at $30^{\circ} \mathrm{C}$ for yeast and fungi.

\section{Results and Discussion}

Taxonomic Studies on Strain No. 3161

Cultural characteristics of strain No. 3161 were as follows. On potato - dextrose agar, the colonies reached a diameter of $6 \sim 8 \mathrm{~cm}$ in 4 weeks. Colonies were white at first, turning pale grayish white with the production of the Sporotrichum stage and then becoming blackish in patches with the formation of the Graphium coremia in clumps. Growth was irregularly zonate. Perithecia were produced abundantly, at first in the aerial hyphae, later in and on the agar, especially to the outside of the colonies in older cultures. Perithecia were black, carbonaceus and subglobose to pyriform on yeast phosphate soluble starch agar and oatmeal agar. Perithecia were $100 \sim 250 \mu \mathrm{m}$ in diameter with papillate ostiole. Hairs formed a dense mat round the perithecium and these were usually short, septate, pigmented, smooth and about $100 \times 1.5 \mu \mathrm{m}$ in diameter. Asci were avoid to broadly clavate, and $18 \sim 30 \times 12$ $\sim 18 \mu \mathrm{m}$ in diameter (Plate 1). Asci were irregularly disposed and walls of asci remained till maturity of the ascospores. Ascospores were plano-convex to concavo-convex in one view, ellipsoid in other view, single-celled, red-brown in color, $8.5 \sim 10 \times 4.5 \sim 5.5 \times 4.0 \sim 4.5 \mu \mathrm{m}$ in size (Plate 2). Ascospores contained a few large oil droplets and several smaller oil droplets and extruded at maturity as a ball at the mouth of the perithecium. Conidial stages were Sporotrichum (Plate 3) and Graphium (Plate 4). Both conidial phases were produced abundantly on potato - dextrose agar. Sporotrichum stage arised

Plate 1. Asci of strain No. 3161.

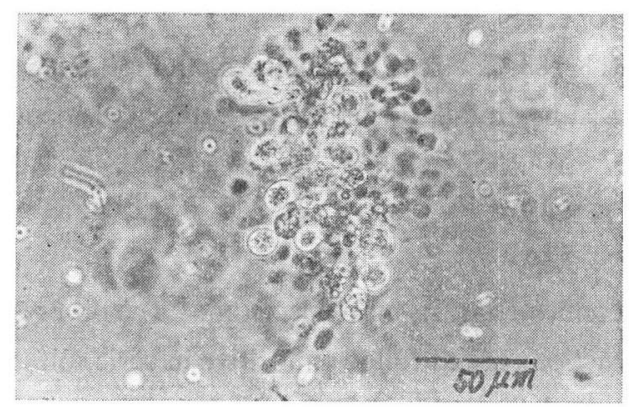

Plate 3. Sporotrichum stage of strain No. 3161.

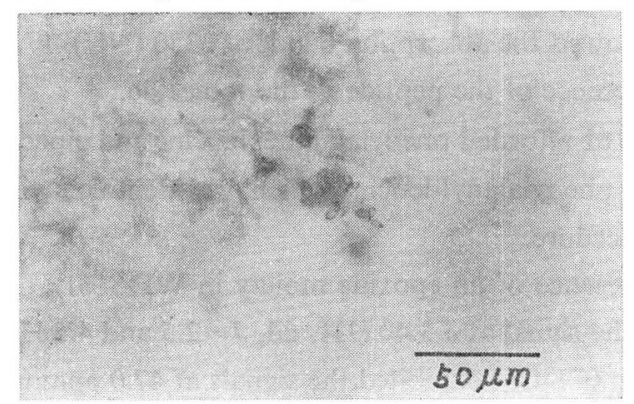

Plate 2. Ascospores of strain No. 3161.

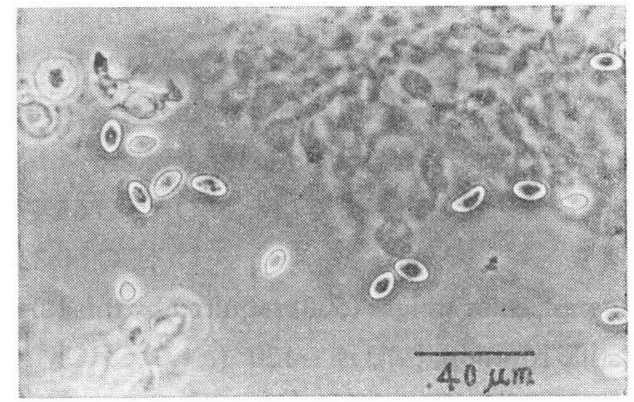

Plate 4. Graphium stage of strain No. 3161.

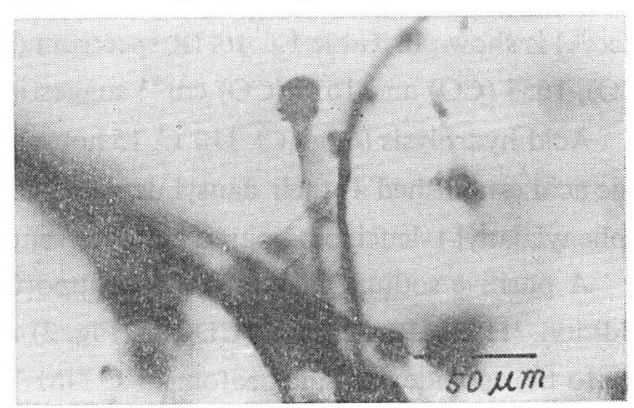


at first with the production of numerous conidiophores from the vegetative hyphae and aerial strands. Conidiophores were simple, hyaline, tapering, up to $30 \mu \mathrm{m}$ long, bearing a number of conidia at the apical end. Conidia readily displaced and were hyaline, variable in shape from pyriform to long cylindrical or wedge-shaped, $5 \sim 10 \times 2 \sim 4 \mu \mathrm{m}$ in size. Graphium stage was evident. Vegetative hyphae grew at right angles to the substrate hyphae. Anastomose and corticate formed coremia which were dark-brown colored, up to $1 \mathrm{~mm}$ high, $6 \sim 25 \mu \mathrm{m}$ in diameter. Coremia were produced single or in clusters. Conidia were similar in shape and size to the Sporotrichum type but averaging slightly larger and more consistently long-cylindrical in shape.

Based on the taxonomical studies, strain No. 3161 was compared with known species described in the report by BARron et al. ${ }^{1)}$ As the result, strain No. 3161 showed a close resemblance to Petriella guttulata and Petriella sordida in conidial and cultural characters. But P. sordida differs in having an extremely hairy, papillate perithecium and distinctive ascospores.

From the above-mentioned informations, strain No. 3161 is considered to be Petriella guttulata.

\section{Isolation of WF-3161}

Fermentation broth (160 liters) was filtered with the aid of filter aid (Radiolite). The filtrate was concentrated in vacuo to 10 liters, and was extracted twice with 10 liters of ethyl acetate after acidification ( $\mathrm{pH}$ 2.0) with $6 \mathrm{~N} \mathrm{HCl}$. The extract was concentrated in vacuo and the crude oily matter obtained was applied to a 1 liter silica gel column. The column was washed with 3 liters of $n$-hexane and 2 liters of a mixture of $n$-hexane - ethyl acetate (1:1), and eluted with ethyl acetate. The fractions containing WF-3161 were combined and concentrated to dryness. The dry residue was dissolved in $50 \mathrm{ml}$ of methanol and applied to a column packed with 1.4 liters NS gel (Nihon Seimitsu Kagaku Co.). When the column was developed with 1.5 to 2.0 liters of methanol, the antibiotic was eluted. After concentration of the active fraction in vacuo the crude solid obtained was crystallized from hot ethanol yielding $420 \mathrm{mg}$ of the antibiotic as colorless needles.

\section{Physicochemical Properties}

WF-3161 forms colorless crystals which melt at $181 \sim 183^{\circ} \mathrm{C}$. It is soluble in methanol, ethanol and chloroform, slightly soluble in benzene and hexane, substantially insoluble in water. Elemental analysis gave the following composition:
Anal. Calcd. for $\mathrm{C}_{31} \mathrm{H}_{44} \mathrm{~N}_{4} \mathrm{O}_{6}$ :
C 65.47, H 7.80, N 9.85.
Found:
C 65.33, H 7.99, N 9.59.

The molecular weight (568) required by this formula was confirmed by its mass spectrum. The observed specific rotation, $[\alpha]_{\mathrm{D}}^{25}$ is $-120^{\circ}\left(c 1.0, \mathrm{CHCl}_{3}\right)$. Color reactions are as follows: positive in ceric sulfate, sodium thiosulfate and iodine, negative in ferric chloride and ninhydrin. The UV spectrum showed end absorption. The Rf value in thin-layer chromatography on a silica gel plate (Kiesel gel 60 F254, Merck) is shown in Table 1. Its IR spectrum (Fig. 1) showed the absorption bands at 3350 (NH), 1710 (CO), $1655(\mathrm{CO})$ and $1635(\mathrm{CO}) \mathrm{cm}^{-1}$ suggesting the presence of the peptide in the molecule.

Acid hydrolysis $\left(6 \mathrm{~N} \mathrm{HCl}, 110^{\circ} \mathrm{C}, 15\right.$ hours) of WF-3161 afforded phenylalanine, leucine and pipecolinic acid established as their dansyl derivatives, and a!so phenylalanyl-leucine which was identified with L-phenylalanyl-L-leucine prepared by a conventional procedure.

A positive sodium thiosulfate test supported the presence of an epoxide moiety in WF-3161. In addition, ${ }^{1} \mathrm{H}$ NMR spectrum $\left(\mathrm{CDCl}_{3}\right)$ (Fig. 2) revealed the signal at $\delta 3.40(1 \mathrm{H}$, dd, $J=2.5$ and $4.5 \mathrm{~Hz})$ due to the epoxide methine proton. ${ }^{13} \mathrm{C}$ NMR spectrum $\left(\mathrm{CDCl}_{3}\right)$ exhibited the signals at $47.0 \mathrm{ppm}(\mathrm{d})$ 
Fig. 1. IR spectrum of WF-3161 (KBr).

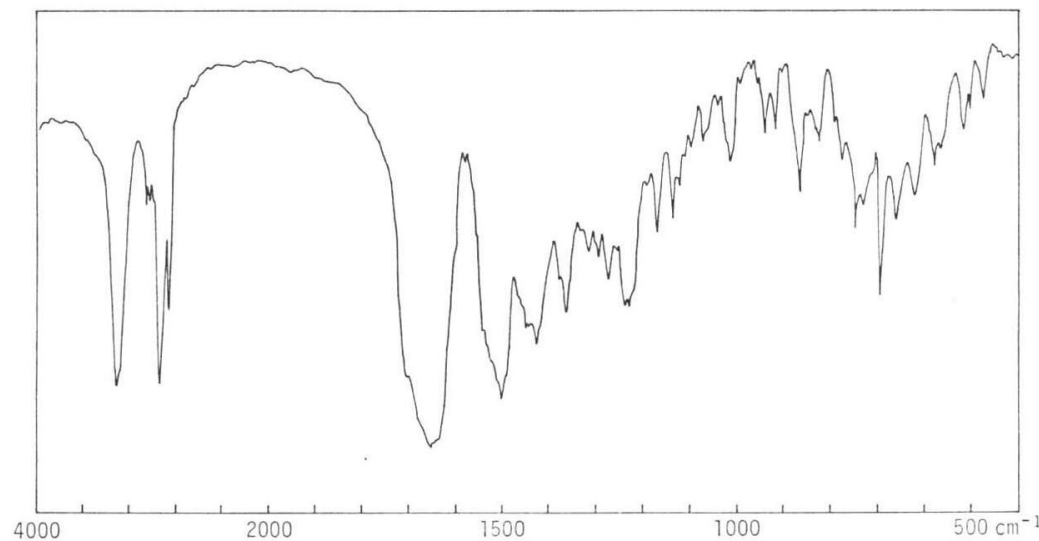

Fig. 2. ${ }^{1} \mathrm{H}$ NMR spectrum of WF-3161 $\left(\mathrm{CDCl}_{3}\right)$.

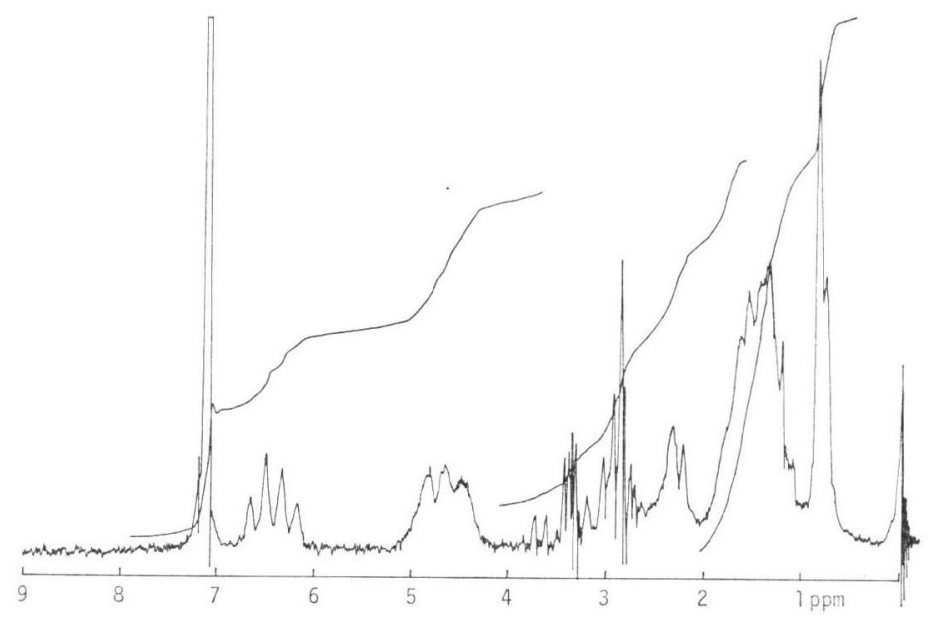

Table 1. Chromatographic properties of WF-3161.

\begin{tabular}{ll}
\hline \multicolumn{1}{c}{ System } & $\mathrm{Rf}$ \\
\hline TLC, silica gel (Merck) & \\
Ethyl acetate & 0.55 \\
Chloroform - methanol (10: 1) & 0.78 \\
\hline
\end{tabular}

and $46.4 \mathrm{ppm}(\mathrm{t})$ attributable to the carbons of the epoxide ring attached to the carbonyl group (208.1 ppm).

Further, the ${ }^{1} \mathrm{H}$ NMR spectrum of WF-3161 exhibited signals at $\delta 0.83(6 \mathrm{H}, \mathrm{d}, J=5 \mathrm{~Hz})$ due to

secondary methyl groups of leucine, at $\delta 4.2 \sim 5.1(5 \mathrm{H}, \mathrm{m})$ assigned to four $\alpha$-methine protons of amino acids (phenylalanine, leucine, pipecolinic acid and 2-amino-8-oxo-9,10-epoxydecanoic acid) and a proton of a methylene of pipecolinic acid, and at $\delta 7.13(5 \mathrm{H}, \mathrm{s})$ for a phenyl group of a phenylalanine unit. In the ${ }^{1} \mathrm{H}$ NMR spectrum a signal pattern of WF-3161 for methylene and methine protons in the region of $\delta 2 \sim 5$ was found to closely resemble that of Cyl-2 except for aromatic methoxyl protons. Cyl-2 is a plant growth regulator which was isolated by TAMURA et al. ${ }^{2)}$ from a culture filtrate of Cylindrocladium scoparium. The structure was deduced by HiRотA et al. ${ }^{3)}$ as shown in Fig. 3. The mass spectrum of WF3161 revealed peaks at $m / z 568\left(\mathrm{M}^{+}\right), 442,399,329,170,120,86$ and 84 (base). The fragmentation pattern in the mass spectrum of WF-3161 resembled that of Cyl-2.4

On the basis of these results WF-3161 has structure as shown in Fig. 4. 
Fig. 3. Structure of Cyl-2.

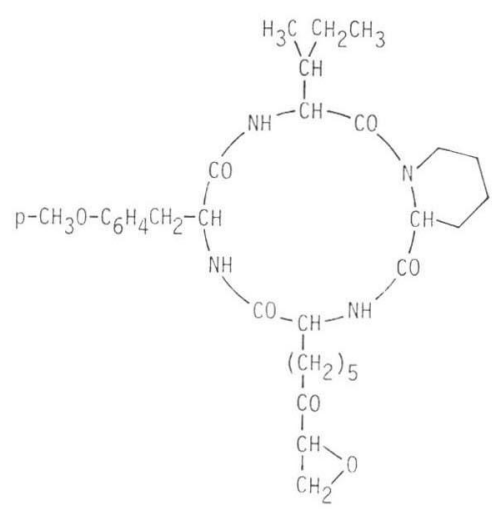

Fig. 5. Structure of chlamydocin.

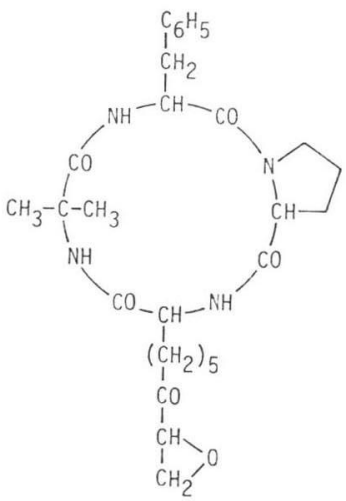

Fig. 4. Structure of WF-3161.

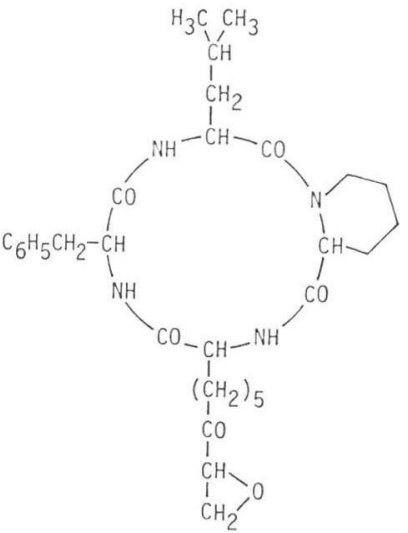

Fig. 6. Structure of HC-toxin.

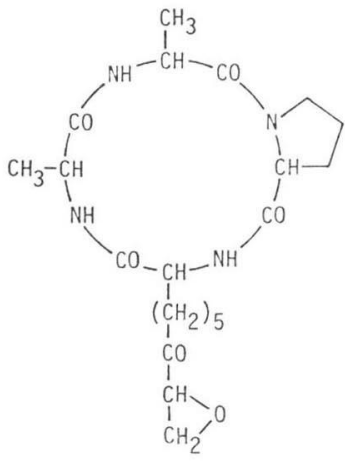

Structually related antibiotics, chlamydocin ${ }^{5,8)}$ (Fig. 5) and HC-toxin ${ }^{7)}$ (Fig. 6) were isolated from cultures of fungal strains. It is very interesting that these cyclic peptides have a unique amino acid, 2amino-8-oxo-9,10-epoxy-decanoic acid in their molecule.

\section{Biological Characteristics}

The antimicrobial spectrum of WF-3161 is shown in Table 2. The antibiotic showed activity against Trichophyton asteroides, but was devoid of any significant antimicrobial activity against other

microorganisms tested.

Antitumor activity of WF-3161 on P-388 leukemia is shown in Table 3. Mice that were implanted with $1 \times 10^{\circ} \mathrm{P}-388$ cells intraperitoneally, 24 hours later received various doses of WF-3161 daily for 4 days after the inoculation. The administration of WF-3161, 12.5 100 mg/ $\mathrm{kg} /$ day, daily for 4 days prolonged the survival period. The administration of $100 \mathrm{mg} / \mathrm{kg} /$ day daily for 4 days caused reduction in body weight.
Table 2. Antimicrobial properties of WF-3161.

\begin{tabular}{lc}
\hline \multicolumn{1}{c}{ Organism } & MIC $(\mu \mathrm{g} / \mathrm{ml})$ \\
\hline Staphylococcus aureus $209 \mathrm{P}$ & $>1,000$ \\
Bacillus subtilis ATCC 6633 & $>1,000$ \\
Escherichia coli NIHJ JC-2 & $>1,000$ \\
Aspergillus niger & $>1,000$ \\
Penicillium chrysogenum & $>1,000$ \\
Candida albicans & $>1,000$ \\
Saccharomyces cerevisiae & $>1,000$ \\
Trichophyton asteroides & 3 \\
\hline
\end{tabular}

Agar dilution method (Nutrient agar for bacteria, Sabouraud dextrose agar for fungi and yeast). 
Table 3. Antitumor activity of WF-3161 against leukemia P-388.

\begin{tabular}{lccccc}
\hline Material & Treatment & $\begin{array}{c}\text { Dose } \\
(\mathrm{mg} / \mathrm{kg} / \text { day })\end{array}$ & $\begin{array}{c}\text { MST } \\
\text { (days) }\end{array}$ & $\begin{array}{c}\text { T/C } \\
(\%)\end{array}$ & $\begin{array}{c}\text { Survivors } \\
\text { (Day 5) }\end{array}$ \\
\hline WF-3161 & q.d. $1 \rightarrow 4$ & 100 & 17.5 & 175 & $10 / 10$ \\
& & 50 & 14.1 & 141 & $10 / 10$ \\
& & 25 & 15.0 & 150 & $10 / 10$ \\
Adriamycin & 12.5 & 13.3 & 133 & $10 / 10$ \\
Control & q.d. $1 \rightarrow 4$ & 6.3 & 10.0 & 100 & $10 / 10$ \\
& & 0.2 & 18.5 & 185 & $10 / 10$ \\
& & $\begin{array}{c}0.5 \% \text { methyl- } \\
\text { cellulose }\end{array}$ & 10.0 & - & $10 / 10$ \\
\hline
\end{tabular}

Tumor inoculum: $1 \times 10^{6}$ ascites cells implanted i.p. on day 0 .

Host : 7-week-old $\mathrm{BDF}_{1}$ mice (ㅇ).

Evaluation : MST $=$ median survival time.

$\mathrm{T} / \mathrm{C} \% \quad:$ MST treated/MST control $\times 100$.

Survivors : Number of survivor/treated.

Criteria $\quad: \mathrm{T} / \mathrm{C} \geq 125$ considered significant antitumor effect.

The $\mathrm{LD}_{50}$ of WF-3161 was estimated to be $200 \mathrm{mg} / \mathrm{kg}$ in $d d \mathrm{Y}$ mice by i.p. route.

Acknowledgment

We are grateful to Dr. A. SuzukI of Department of Agricultural Chemistry, The University of Tokyo, for the generous supply of an authentic specimen of Cyl-2.

\section{References}

1) Barron, G. L.; R. F. Cain \& J. C. Gilman: A revision of the genus Petriella. Can. J. Botany 39: 837, 1961

2) Hirota, A.; A. Suzuki, H. Suzuki \& S. Tamura: Isolation and biological activity of Cyl-2, a metabolite of Cylindrocladium scoparium. Agric. Biol. Chem. 37: 643 647, 1973

3) Hirota, A.; A. Suzuki, K. Aizawa \& S. Tamura: Structure of Cyl-2, a novel cyclopeptide from Cylindrocladium scoparium. Agric. Biol. Chem. 37: 955 956, 1973

4) Hirota, A.; A. Suzuki, K. Aizawa \& S. Tamura: Mass spectrometric determination of amino acid sequence in Cyl-2, a novel cyclotetrapeptide from Cylindrocladium scoparium. Biomed. Mass Spectrom. 1: $15 \sim 19,1974$

5) Closse, A. \& R. Hugenin: Isolation and structure elucidation of chlamydocin. Helv. Chim. Acta 57: $60 \sim 61,1974$

6) Stahelin, H. \& A. Trippmacher: Cytostatic activity of chlamydocin, a rapidly inactivated cyclic tetrapeptide. Eur. J. Cancer 10: 801 808, 1974

7) Liesch, J.; C. Sweeley, G. Staffled. M. Anderson, D. Weber \& R. Scheffer: Structure of HC-toxin, a cyclic tetrapeptide from Helminthosporium carbonum. Tetrahedron 38: 45 48, 1982 